\title{
Study of Change in Knowledge and Attitude of Secondary School Teachers toward Adolescent Reproductive Health Education after Training Program in Rural Schools of Wardha District, Maharashtra
}

\author{
${ }^{1}$ Neema Acharya, ${ }^{2}$ Sabiha, ${ }^{3} \mathrm{C}$ Hariharan, ${ }^{4}$ Shaveta Gupta, ${ }^{5}$ Rutuja Athavale
}

\begin{abstract}
This study assessed the effect of training program on teachers' knowledge of and attitude toward reproductive health education/ sexuality education (RHE/SE) in five randomly selected rural schools in rural area of Wardha district, Maharashtra, India. All the 40 teachers in the selected were recruited for the study. They (40 teachers) were all given training in RHE/SE for 1 month. Their knowledge and attitude toward RHE/SE were assessed pre-and post-training program. The results show a significant increase in percentage of those who had good knowledge in general areas of RHE/SE at post-training assessment compared with pretraining assessment [from $14.3 \%$ to $53.6 \%, p=0.0001$ ). Also, pre-post attitudinal disposition assessments show that there was an increase in percentage of those who were favorably disposed to the teaching of RHE/SE. The study suggests that RHE/SE should be included and made compulsory in all training program for all teachers in india.
\end{abstract}

Keywords: Adolescent health, Reproductive health, School health, Sex education.

How to cite this article: Acharya N, Sabiha, Hariharan C, Gupta $S$, Athavale R. Study of Change in Knowledge and Attitude of Secondary School Teachers toward Adolescent Reproductive Health Education after Training Program in Rural Schools of Wardha District, Maharashtra. J South Asian Feder Obst Gynae 2014;6(2):98-100.

Source of support: Nil

Conflict of interest: None declared

\section{INTRODUCTION}

Adolescents in India as in other countries of the world are facing many reproductive health problems nowadays. Some of these problems are, high rate of high risk-sexual activities, unwanted pregnancy, abortion, STIs/HIV/AIDS and

${ }^{1}$ Professor, ${ }^{2}$ Intern, ${ }^{3}$ Professor and Head, ${ }^{4,5}$ Junior Resident

${ }^{1-5}$ Department of Obstetrics and Gynecology, Datta Meghe Institute of Medical Sciences (Deemed University), Wardha Maharashtra, India

Corresponding Author: Neema Acharya, Professor Department of Obstetrics and Gynecology, Datta Meghe Institute of Medical Sciences (Deemed University), Wardha442004, Maharashtra, India, e-mail: neemadk@hotmail.com school drop-out. ${ }^{1-7}$ Some factors which were implicated as being responsible for these reproductive health problems are, change in traditional moral values nowadays, negative peer group influence, love of money, women's economic dependence on men, desire to be loved, effect of western cultures, such as pornographic films available on internet and finally poor knowledge of reproductive health education/sexuality education (RHE/SE).

To address these problems, constant suggestions and recommendations have been made by previous researchers for the introduction of compulsory RHE/SE at all levels of the educational institutions throughout India.

\section{Essence of this Study}

These studies were mainly carried out in African countries particularly Nigeria. In India there, are very few studies done on this topic in spite of similar behavioral patterns found in rural as well as urban youth. Parents, teachers and peer group can create a good amount of awareness among youth regarding the sexual and reproductive health of the younger generation and thus have a positive impact on the social development of our country.

This age group spends major amount of their time in school and idolize their teachers as role models. Teachers could be the one of the best counselers for their various queries about the physical and mental changes acuring in this age group. Standard curricula of school teaching does make teachers training in these aspects and the teachers have their own hesitations and myths about imparting reproductive health education to these children at this age.

Hence, this study was carried out to know the change in knowledge and attitude of secondary schools teachers toward adolescent reproductive health education after training program.

\section{AIMS AND OBJECTIVES}

1. To assess the teachers' level of knowledge of RHE/SE before and after the training program.

2. To assess their attitudinal disposition toward the introduction of RHE/SE into the curriculum of secondary schools in India before and after the training program. 
3. To equip them with adequate knowledge of RHE/SE to enable them function effectively as trainers (Service providers) in the proposed school-based adolescent RHE coming up shortly in their respective schools.

\section{MATERIALS AND METHODS}

The study was carried out among teachers of five rural secondary schools in Wardha district of Maharashtra, India. The study included training of 40 teachers. Data collection was done in two phases. The first phase was before the training (base-line data) of the teachers in the area of adolescent reproductive health, while the second phase was after the training (post-training data). The training was carried out for a period of 2 months.

The curriculum for the training was developed after due consultation with expert in adolescent reproductive health and standard books on training manual and facilitators' guide on adolescent reproductive health. ${ }^{8,9}$

The curriculum for training included following:

1. Description and functions of human reproductive organs
2. Concept of adolescent and puberty

3. Teenage pregnancy: associated problems and prevention

4. Abortion, its associated problems and prevention

5. STIS/HIV/AIDS causes and prevention

6. Contraceptives for the adolescents

7. Communication skills (self-assertive/esteem skills).

8. Goal setting and life skills.

The training was handled by teaching staff of department of obstetrics and gynecology of DMIMSU with author being the lead teacher. The study was approved by the ethical committee and from the respective school authorities.Informed consent was obtained from the participating teachers.

Data collection was done through small group discussion (SGD) and self-administered feedback questionnaire.

The questionnaire were based on the collected information included demographic data, knowledge of concept of adolescent and human reproductive organs, knowledge of STIs and HIV/AIDS, knowledge of contraceptives and attitude toward contraceptive use by adolescents and attitude toward the teaching of RHE/SE in rural schools of Wardha.

\section{RESULTS}

Table 1: Personal feelings of teachers on following issues

\begin{tabular}{lll}
\hline Personal feelings & Pretraining $(N)$ & Post-training $(N)$ \\
\hline Need of training & 35 & 40 \\
Teachers can counsel & 10 & 38 \\
Teenage pregnancy & 37 & 40 \\
Abortion in adolescents & 0 & 40 \\
STI/HIVIAIDS in adolescents & 31 & 40 \\
Contraceptives for the adolescents & 0 & 40 \\
\hline
\end{tabular}

Table 2: Level knowledge of concept of adolescence and reproductive health (Likert 5-point scale)

\begin{tabular}{lll}
\hline Parameters & Pretraining & Post-training \\
\hline Knowledge of adolescence & 1 & 4 \\
Knowledge of puberty & 1 & 4 \\
Knowledge of menarche & 1 & 4 \\
Knowledge of human reproductive organs & 1 & 4 \\
General knowledge of RHE/SE & 1 & 4 \\
Knowledge of STIs and HIVIAIDS & 1 & 5 \\
\hline
\end{tabular}

Table 3: Attitude of teachers (Likert point scale 1-5)

\begin{tabular}{lll}
\hline Attitude of teachers & Pre-training & Post-training \\
\hline Importance of RHE/SE & 3 & 5 \\
Need of inclusion of RHE/SE in regular health awareness program & 1 & 5 \\
Importance of counseling adolescent boys/girls about RHE/SE in school & 2 & 5 \\
Teacher can be one of the best person to educate/council adolescents & 1 & 5 \\
Accurate information about human sexuality & 1 & 4 \\
Effective classroom skills & 1 & 4 \\
Advise on teaching materials and methods & 1 & 5 \\
Information on school and community policies & 1 & 5 \\
Personal comfort with reproductive and sexual health issues & 5 \\
\hline
\end{tabular}




\section{DISCUSSION}

As shown in our study 40 secondary school teachers of rural schools of Wardha district were benefitted through this program.

As shown in Tables 1 and 2, a general trend of an increase in the percentage of those who had the correct knowledge in all area of RHE/SE was obtained after post-training assessment, when compared with pre-training assessments. There was a significant change in the attitude of teachers toward the need of sex education in school as shown in Table 3. Two facts emerge from these differential results between pre- and post training assessments.

Firstly, it is a pointer to the fact that teachers (especially in rural areas) were still ill equipped to handle the proposed RHE/SE which is yet to be introduced into Indian schools as found in the previous studies, 2,3

Secondly, it underscores the fact that teachers still need sound training in all aspects of RHE/SE before they can effectively handle the subject-matter.

Thirdly, as observed in our study, their low level of attitudinal disposition at pre-training assessment (17.9\%)toward the teaching of RHE/SE in Indian schools is at variance with the previous studies. ${ }^{4,5}$ The reason that can be advanced for this is that the previous studies were carried out in urban areas whereas our study was done in the rural area.

The conclusion from our study is that teachers of schools of Wardha in India (especially in the rural areas) need to undergo a thorough training in all areas of RHE/SE including promotion of condom use among adolescents. This will equip them in handling the subject-matter effectively in their respective schools. ${ }^{6,7}$

Therefore, in view of our findings, it is hereby recommended that more effort should be put at 'educating' the teachers to raise their acceptance attitude to teaching them this type of sex education higher than the $45 \%$ achieved in this study. In order to achieve this, RHE/SE should be included and made compulsory in the training program for all teachers in India. And those already on the job should always undergo periodic seminars and refresher courses on this subject-matter.

\section{IMPLICATIONS}

Urban youth is quite aware about reproductive health education as compared to rural youth. Such studies help to create awareness among rural adolescents through teachers's guidance. By training secondary school teachers we can make as an excellent catalyst system in schools in the process of generating awareness and concern about the reproductive health and the rise in incidence of STIs/HIV in India.

\section{REFERENCES}

1. Handbook for Educating on Adolescent Reproductive and Sexual Health, UNESCO PROAP Regional Clearing House on Population Education and Communication United Nations Population Fund, Bangkok, 1998.

2. National Population Education Project, New Delhi (1992). General Framework of Adolescence Education, Adolescence Education in Schools Part - 1. New Delhi: National Population Education Project, NCERT.

3. Oronsaye AU, Odiase GI. Attitudes toward abortion and contraception among Nigerian secondary school girls. Int J Gynaecol Obstet 1983 Oct;21(5):423-426.

4. Population Reference Bureau (PRB) and centre for population options (CPO). The world's youth: A special focus on reproductive health-Wall Chart, Washington DC, 1994.

5. Kenya Demographic and Health Surveys (KDHS) (1998).

6. Network Programmes for adolescents: sex education helps prepare young adults. Fam Health Inter 2000;20(3):13-14.

7. Adolescent Health and Development. National Training Manual being developed through joint effort of FMOH/UNFPA/WHO (draft), Nigeria 2001.

8. DSW (Deutsche Stiftung Weltbevoelkerung), Sexual and Reproductive Health Facilitators' Training Manual, 2013.

9. IEC-Govt of India, Adolescent-Friendly Reproductive and Sexual Health Services, Facilitators Guide. 